\title{
Selinexor, a selective inhibitor of nuclear export (SINE), shows enhanced activity in combination with PD-1/PD-L1 blockade in syngeneic murine models of colon cancer and melanoma
}

\author{
Matthew R Farren ${ }^{1 *}$, Reena Shakya ${ }^{2}$, Rebecca Hennessey ${ }^{3}$, Thomas Mace ${ }^{4}$, Jennifer Yang ${ }^{1}$, Omar Elnaggar ${ }^{1}$, \\ Gregory Young ${ }^{5}$, Yosef Landesman ${ }^{6}$, Robert Carlson 6 , Sivan Elloul ${ }^{6}$, Marsha Crochiere ${ }^{6}$, Christin Burd ${ }^{3}$, \\ Gregory Lesinski ${ }^{1}$
}

From 30th Annual Meeting and Associated Programs of the Society for Immunotherapy of Cancer (SITC 2015) National Harbor, MD, USA. 4-8 November 2015

Exportin-1 (XPO1) is a nuclear export protein with $>220$ cargo proteins, including tumor suppressors and cell cycle modulators. Selinexor is a SINE (Selective Inhibitor of Nuclear Export) compound that has been administered to $>900$ cancer patients in Phase I and II trials to date, with evidence of efficacy and tolerability. Selinexor blocks nuclear export of NFAT1c, STAT1 and STAT3, which are implicated in regulating the inhibitory $\mathrm{T}$ cell receptor PD-1 and its ligand, PD-L1. We hypothesized that selinexor would upregulate $\mathrm{T}$ cell checkpoint molecule expression, and that combination treatment with antiPD-1 or anti-PD-L1 would thereby enhance the ability of selinexor to elicit antitumor activity.

Selinexor increased PD-1 gene expression by $\sim 2$-fold in normal lymphocytes and induced PD-L1 gene expression in tumor cell lines. Mice bearing syngeneic colon tumors (colon26) treated with selinexor and anti-PD-1 for 2 weeks demonstrated a significant reduction in tumor growth rate $(\mathrm{P}<0.05)$, while monotherapy with either agent had no significant effect on tumor growth. Similar results were obtained in mice bearing syngeneic B16F10 melanoma tumors, whereby combined treatment with selinexor + anti-PD-1 was superior to either single agent alone $(\mathrm{p}<0.034)$. Combined therapy of mice bearing B16F10 tumors with selinexor and anti-PD-L1 was similarly effective, with significantly smaller tumors

'Department of Internal Medicine, James Comprehensive Cancer Center, The Ohio State University, Columbus, OH, USA

Full list of author information is available at the end of the article at the study endpoint $(\mathrm{p}<0.001)$. No weight loss or signs of toxicity were evident in any in vivo study.

Immunophenotypic analysis by flow cytometry revealed that selinexor alone or in combination with anti-PD-1/anti-PD-L1 significantly increased the percentage of splenic NK cells $(\mathrm{p} \leq 0.050)$, while selinexor \pm anti-PD-L1 significantly increased the percentage of splenic Th1 T cells $(\mathrm{p} \leq 0.011)$, all compared to vehicle treated mice. Interestingly, combining selinexor with anti-PD-L1 significantly decreased the percentage of splenocytes that expressed PD-L1 $(\mathrm{p}<0.001)$. These data indicate that the efficacy of selinexor may be enhanced by disrupting the pre-existing PD-1/PD-L1 signaling in effector cells ( $\mathrm{T}$ and NK cells).

Altogether, these data suggest that the efficacy of selinexor in combination with anti-PD-1 or anti PD L1 in mouse syngeneic tumor models may be due to both disrupting immunosuppressive PD-1/PD-L1 signaling and increasing the frequency of potentially tumor reactive NK cells and Th1 T cells. This provides a rational basis for this treatment combination as a novel therapeutic approach for advanced cancer.

\footnotetext{
Authors' details

'Department of Internal Medicine, James Comprehensive Cancer Center, The Ohio State University, Columbus, OH, USA. ${ }^{2}$ The Ohio State University, Columbus, OH, USA. ${ }^{3}$ Department of Molecular Genetics, James Comprehensive Cancer Center, The Ohio State University, Columbus, $\mathrm{OH}$, USA. ${ }^{4}$ Department of Internal Medicine, James Comprehensive Cancer Center, The Ohio State University, Columbus, OH, USA. ${ }^{5}$ Center for Biostatistics, The Ohio State University, Columbus, OH, USA. ${ }^{6}$ Karyopharm Therapeutics, Newton, MA, USA.
} 
doi:10.1186/2051-1426-3-S2-P355

Cite this article as: Farren et al: Selinexor, a selective inhibitor of nuclear export (SINE), shows enhanced activity in combination with PD-1/PD-L1 blockade in syngeneic murine models of colon cancer and melanoma. Journal for ImmunoTherapy of Cancer 2015 3(Suppl 2):P355.

Submit your next manuscript to BioMed Central and take full advantage of:

- Convenient online submission

- Thorough peer review

- No space constraints or color figure charges

- Immediate publication on acceptance

- Inclusion in PubMed, CAS, Scopus and Google Scholar

- Research which is freely available for redistribution

Submit your manuscript at www.biomedcentral.com/submit
() Biomed Central 